\title{
Quenching residual stresses in T-section 7050 aluminum alloy forging
}

\author{
Gong Hai*,**,***, Wu Yunxin*,**,***, Zhang Tao*,**, Liu Yaoqiong**,****, Li Chen****, \\ Ji Hao****, Yi Shouhua*,**, Cao Minghui*,**, Xiao Feng*,** \\ *State Key Laboratory of High Performance Complex Manufacturing, Central South University, Changsha 10083, China, \\ E-mail: gonghai@csu.edu.cn \\ **School of Mechanical and Electrical Engineering, Central South University, Changsha 410083, China, \\ E-mail: wuyunxin@csu.edu.cn \\ ***Nonferrous Metal Oriented Advanced Structural Materials and Manufacturing Cooperative Innovation Center, Cent- \\ ral South University, Changsha 410083, China, E-mail: gonghai@csu.edu.cn \\ ****Avic The First Aircraft Institute, Xi'an 710000, China, E-mail: lyq4833@qq.com \\ cross $^{r e f}$ http://dx.doi.org/10.5755/j01.mech.23.3.14259
}

\section{Introduction}

7050 aluminum alloy is widely used in aerospace, and T-section $\mathrm{Al} 7050$ forgings are used for manufacturing the connecting part of wing and fuselage, owing to their high specific strength, toughness and good corrosion resistance in many environments $[1,2]$. While in the manufacturing processes of aluminum alloy forgings especially in the quenching process, high residual stresses are introduced inevitably, which cannot be thermally relieved while maintaining the alloy's favorable mechanical properties, and cannot be relieved by traditional pre-stretching as aluminum plate due to their complex structure. The existence of unknown residual stresses in the aluminum alloy forgings is a major reason leading to serious deformation after the forgings are machined to components, which is fatal to the aerospace manufacturing. Thus, to obtain the distributions of quenching residual stresses in aluminum alloy forgings is very important.

A variety of methods is used to study the residual stress by researchers. Numerical simulation is widely used to analyze the quenching residual stresses in aluminum alloy, the predicted results showed good agreement with the experimental values of residual stresses [3, 4]. Experimental measurement is a direct method for measuring the distribution of residual stresses in materials, which is a necessary verification of numerical simulation. A wide range of residual stress measurement techniques are available for the characterization of residual stresses in engineering components [5], but few are available to measure the whole stress distribution within materials with complicated contour. The hole-drilling method [6] and X-ray diffraction (XRD) method [7] can only be used to determine the surface residual stresses. The slitting method [8] and layer removal method [9] can be used to determine the internal residual stresses in components like plate, with a nearly two-dimensional distributed residual stresses. The contour method provides a two-dimensional map of residual stresses on a cut surface, which has been applied to measuring internal residual stresses in welding joints [10, 11], 2026-T3511 aluminum alloy component [12] and die forging 7050-T74 aluminum alloy component [13]. Neutron diffraction is a popular non-destructive technique that has been used to map multiaxial components of stresses in engineering components [14-16], but its application is limited mostly by the need to take components to a neutron residual stress diffract meter.
In this work, quenching residual stresses in T-section 7050 aluminum alloy forging were studied by a combination using of finite element analysis and three experimental methods according to the forging geometry. In the finite element analysis, the overall distribution of residual stresses in the forging was obtained, and the maximum stress and its corresponding distribution region were found. In the measurement, residual stresses normal to the whole T-section were measured using the contour method, stresses in the wing plate area were measured using the layer removal method and surface stresses were measured using Xray diffraction. By comparative analysis of the measurement results and FEM result with each other, the distribution of residual stresses in the forging was determined. It provides important information for the stress reduction of forgings.

\section{Finite element analysis}

Quenching is a solid solution strengthening method to improve the performance of materials where a hot metal part is cooled down rapidly with the help of quenchant such as water, oil, other liquids, or combinations of them. Finite element analysis of the quenching process for $\mathrm{T}$-section 7050 aluminum alloy forging was performed, as this type of forgings were commonly used as the raw material for machining to manufacture aircraft structures, and encountered a serious problem of processing deformation caused by residual stresses.

For the quenching process, finite element analysis conditions were taken from actual producing, in which $\mathrm{Al}$ 7050 forging with a uniform temperature of $475^{\circ} \mathrm{C}$ was immersed in water at a temperature of about $25^{\circ} \mathrm{C}$ until the forging was cooled down to a uniform temperature. In order to obtain the quenching stresses, we need to obtain the material parameters corresponding to the quenching state, and tests were conducted within 20 minutes after the 7050 aluminum alloy specimens were quenched. The material properties used in this study are listed in Table 1. It is worth noting that the yield strength $\left(\sigma_{0.2}\right)$ of $7050 \mathrm{~T} 73652$ at room temperature $\left(24^{\circ} \mathrm{C}\right)$ is up to $455 \mathrm{MPa}$ [17], which is much larger than the yield strength of $\mathrm{Al} 7050$ at the end of quenching, as shown in Table 1, and taking use of incorrect yield strength in the simulation will results in inaccurate result of quenching residual stresses.

A coupled FE analysis of temperature and stresses was conducted to determine the temperature variations of 
the T-section 7050 aluminum alloy forging and residual stresses due to temperature changes using MSC.Marc. It was assumed that there were no stresses in the forging at the beginning of quenching since the forging was heated and held at $475^{\circ} \mathrm{C}$, which is above the recrystallization temperature of 7050 aluminum alloys.

T-section 7050 aluminum forging with an overall size of $500 \mathrm{~mm} \times 420 \mathrm{~mm} \times 150 \mathrm{~mm}$ was used in the finite element analysis through comparison with experimental measurements conducted using contour method, layer removal method and X-ray diffraction in this study, as illustrated in Fig. 1. Fig. 1 also shows the schematic diagram of internal residual stresses measurement for 7050 aluminum alloy forging, and the plane where residual stresses in the $x$, $y$, and $z$ directions were measured and reported.

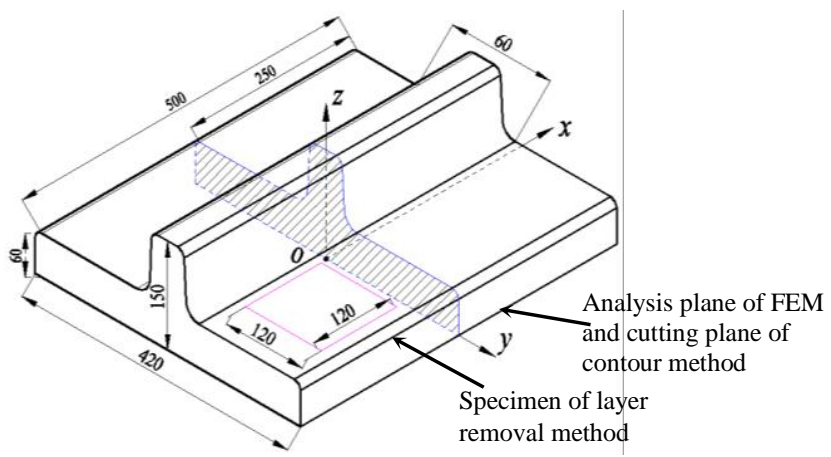

Fig. 1 Schematic diagram of quenching residual stresses study for 7050 aluminum alloy forging

\section{Experiment details}

\subsection{Experiment scheme}

As a comparison of the finite element simulation, quenching experiment and residual stresses measurement of T-section 7050 aluminum alloy forging were conducted. After solution heat treatment the forging was immerging quenched in $25^{\circ} \mathrm{C}$ water, and then residual stresses of the forging induced by quenching were measured using contour method, layer removal method and X-ray diffraction method. The residual stresses measurement schematic of the forging is shown in Fig. 1. First, surface stresses of the forging were measured using X-ray diffraction. Then with a cut along the plane shown in Fig. 1, $x$-direction residual stresses on the cross-section were measured using contour method. At last, a specimen was cut from the wing plate area of the forging for residual stress measurement using the layer removal method. All the measurement results and FEM result of residual stresses were compared with each other.

\subsection{Contour method}

The contour method determines residual stresses through an experiment that involves carefully cutting a specimen into two pieces, measuring the resulting surface contour due to residual stresses release, data processing and an inverse calculation of residual stresses using FEM $[11,18]$.

In the contour method the measured specimen is carefully cut into two pieces at first. It is assumed in the contour method that the cutting surface is a plane before cutting (as shown in Fig. 1), materials are in elastic state in the stresses releasing process. And mechanical cutting has no effect on the deformation, thus, in the cutting process the plane surface will become a non planar contour with the release of residual stresses in the original cutting surface. The contour datum of the cutting surface is measured and translated to displacement datum. Then the displacement data is used to compute residual stresses through an analysis that involves a finite element model of half the specimen. As part of the analysis, the opposite of the displacement datum are imposed as a set of displacement boundary conditions on the model. The finite element model accounts for the stiffness of the material and part geometry to provide a unique result. The output is a two-dimensional map of residual stresses normal to the measurement plane.

Table 1

Mechanical and thermal properties of $\mathrm{Al} 7050$ at different temperatures

\begin{tabular}{|c|c|c|c|c|c|c|c|}
\hline $\begin{array}{c}\text { Test } \\
\text { temperature } \\
T,{ }^{\circ} \mathrm{C}\end{array}$ & $\begin{array}{c}\text { Yield strength } \\
\sigma_{0.2}, \mathrm{MPa}\end{array}$ & $\begin{array}{c}\text { Elastic } \\
\text { Modulus } \\
E, \mathrm{GPa}\end{array}$ & $\begin{array}{c}\text { Specific heat } \\
c, \mathrm{~J} / \mathrm{g} \cdot{ }^{\circ} \mathrm{C}\end{array}$ & $\begin{array}{c}\text { Thermal dif- } \\
\text { fusivity } D, \\
\mathrm{~mm} / \mathrm{s}\end{array}$ & $\begin{array}{c}\text { Thermal } \\
\text { conductivity } \\
\lambda, \mathrm{W} / \mathrm{m} \cdot{ }^{\circ} \mathrm{C}\end{array}$ & $\begin{array}{c}\text { Thermal ex- } \\
\text { pansion } \alpha, \\
10^{-6} /{ }^{\circ} \mathrm{C}\end{array}$ & $\begin{array}{c}\text { Convection coefficient } \\
h(\mathrm{Al} \text { and water), } \\
\mathrm{kW} / \mathrm{m}^{2} \cdot{ }^{\circ} \mathrm{C}\end{array}$ \\
\hline 20 & 158.4 & 71.2 & 0.79 & 53.31 & 119.95 & 21.75 & 0.60 \\
\hline 100 & 138.5 & 65.2 & 0.79 & 53.53 & 119.59 & 23.62 & 5.70 \\
\hline 200 & 108.7 & 56.3 & 0.84 & 54.75 & 129.51 & 24.53 & 16.53 \\
\hline 300 & 64.4 & 38.5 & 0.87 & 53.81 & 131.68 & 25.52 & 16.83 \\
\hline 400 & 42.6 & 31.2 & 0.78 & 47.58 & 104.95 & 26.64 & 7.66 \\
\hline 475 & 22.8 & 24.6 & 0.91 & 43.57 & 111.55 & 27.63 & 4.50 \\
\hline
\end{tabular}

1) Specimen cutting. Before cutting, the forging was fixed at the two ends of $x$ direction, and a $\phi 5 \mathrm{~mm}$ hole through the full thickness was drilled in the cutting path at each end of $y$ direction to prevent cutting surface closure due to release of compressive stresses, which may influence the following cutting process. Then a high precision electrical discharge machining (EDM) machine tool DK7625P was used to cut the forging into two parts along the cross section to be studied. By using a $\phi 0.2 \mathrm{~mm}$ copper wire and a lowspeed cutting of about $1 \mathrm{~mm} / \mathrm{s}$, the roughness of the cutting surface after EDM machining is about Ra $0.4 \mu \mathrm{m}$.
2) Contour measurement of the cutting surface. A MQ8106 global coordinate measuring machine (CMM) with measuring resolution of about $0.1 \mu \mathrm{m}$ was used to measure the profile of the resulting surface. Surface profiles of both two halves of the forging were measured, and the locations of the measuring points on the two surfaces were set the same. The distances between the measuring points of both $y$ and $z$ direction were $5 \mathrm{~mm}$.

3) Surface contour data processing. Measured contour datum of the cutting surface were converted to defor- 
mation datum in a common coordinate system, then the deformation datum at the two surfaces were averaged in order to eliminate the measurement error and machining error. Then, the averaged datum was smoothed by spline fitting algorithm and Fourier surface fitting. Furthermore, a test cut was made in a stressfree region of the part and the resulting surface contour measured was used to correct the former result. Measured contour datum and processed datum are shown in Fig. 2 and Fig. 3 respectively.

4) Inverse calculation of residual stresses by FEM. A finite element model of one-half forging was built to calculate the residual stresses normal to the original cutting plane using linear elastic analysis. The smoothed deformation datum was applied to the previous flat cutting plane in the finite element model as boundary condition. The material behavior is isotropic and linear elastic with an elastic modulus of $71 \mathrm{GPa}$ and Poisson ratio of 0.33 . Additional constraints are adopted to prevent rigid-body motions of the finite element model.

\subsection{Layer removal method}

The mechanical model of layer removal method is shown in Fig. 4. It is assumed in the layer removal method that residual stresses in the specimen are equal at the same thickness, and only vary with specimen thickness. The measurement procedure of the layer removal method contains three steps: specimen preparation, layer removal and strain measurement, residual stresses inverse calculation.

First, specimen of size $120 \mathrm{~mm} \times 120 \mathrm{~mm} \times 60 \mathrm{~mm}$ was cut from the wing plate area of the forging by electrical discharge machining, as shown in Fig. 1. Strain gages BX120-5AA with active gage dimension of $5 \mathrm{~mm} \times 3 \mathrm{~mm}$ and sensitivity coefficient of $2.08 \pm 0.1 \%$ were fixed at the bottom surface of the specimen in both $x$ direction and $y$ direction, and sealed with waterproof glue to prevent moisture in subsequent operations. Then, the specimen was clamped on a LEADWELL V-60A CNC machining center, and strain gages were connected to a TS3861 strain gage instrument, which test accuracy is about $1 \mu \varepsilon$.

Then surface material of the specimen was stripped off layer by layer (about $3 \mathrm{~mm}$ each layer) from top to bottom with milling cutter rotate speed $1000 \mathrm{r} / \mathrm{min}$ and feed speed $50 \mathrm{~mm} / \mathrm{min}$, which changed the equilibrium of force and torque in the remaining part. Strains $\varepsilon_{x}$ and $\varepsilon_{y}$ at the bottom of the specimen were induced because of the release of residual stresses in the specimen. After each layer was removed the clamps were uninstalled for the specimen to cool down and stresses to relax fully, then strains were recorded when they were stable. It is assumed that additional machining stresses were not introduced, and only elastic deformation occurred in the cutting process, thus measured strains are only the result of the release of the residual stresses in the removed layers. Measured strains corresponding to the removed layers are shown in Fig. 5.

According to the theory of elasticity, the initial residual stresses in the removed layers can be obtained from the measured strains. Using a reverse solution, the inner residual stresses can be calculated with the strain datum. The relationship between the residual stresses and measured strains [9] can be expressed as: $\sigma_{x, y}(z)=\frac{E}{2}\left[(H-t) \frac{d \varepsilon}{d t}-4 \varepsilon+6(H-t) \int_{0}^{t} \frac{\varepsilon}{\left(H-z^{2}\right)} d z\right]$

where $E$ is Elastic modulus of the material, $\varepsilon$ is fitting function of measured strains, $t$ is thickness of a removed layer, $H$ is total thickness of the specimen. The original residual stresses in the removed layers can be calculated from the measured strains according to Eq. (1).

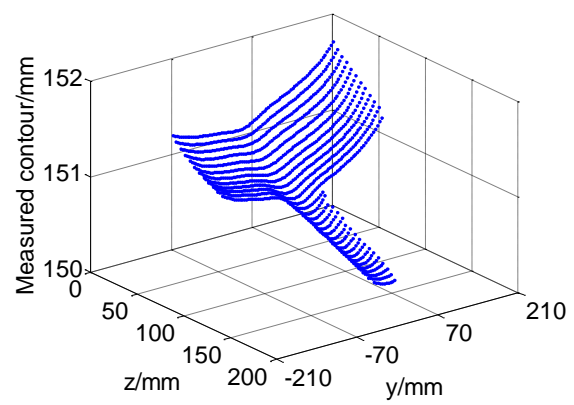

Fig. 2 Measured contour datum of the cutting surface

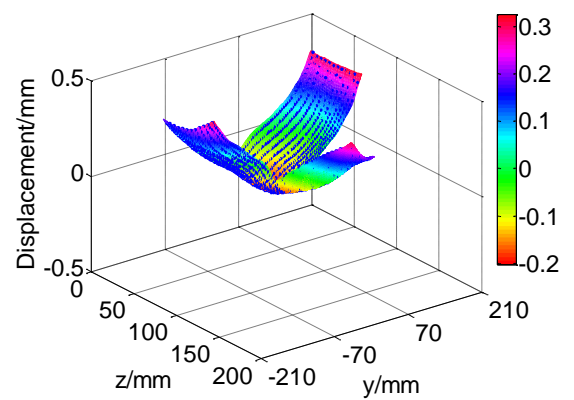

Fig. 3 Surface displacement after data processing

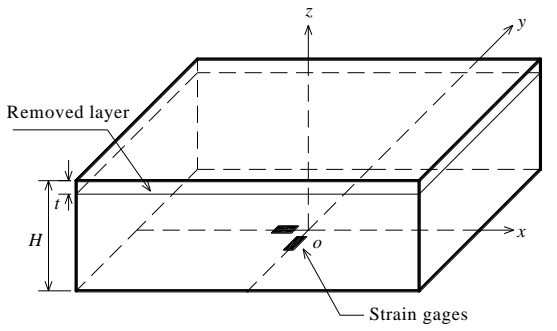

Fig. 4 Principle diagram of layer removal method

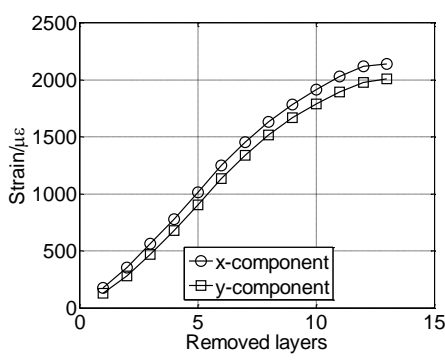

Fig. 5 Measured strains in layer removal method

\section{Results and discussion}

Fig. 6-8 illustrate the FEM results of $x$-, $y$ - and $z-$ component quenching residual stresses on the T-section shown in Fig. 1 coincidence with the cutting plane of contour method. In the three figures, residual stresses in the analyzed section present a obvious layering distribution, with 
compressive stresses at surface and tensile stresses in the core, and the layers are approximately parallel to the surface of the T-shaped cross section. In the wing plate area, as the heat transfer can be simplified as a two-dimension problem during the quenching process, the distribution of residual stresses is similar to that in a thick plate [1], which is approximately symmetrical along the thickness direction, $x$ and $y$-component stresses are very close at the same point. While the $z$-component stresses are relatively small. In the quenching process, as the cross-area is cooled down by three-dimension heat transfer, results in rather complex distribution of stresses.

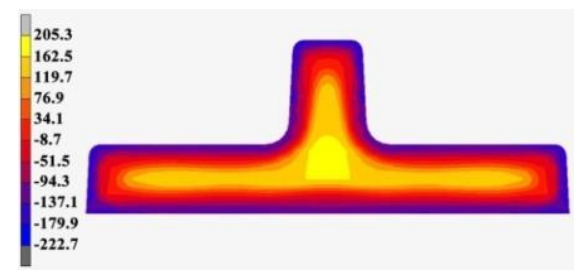

Fig. 6 FEM result of $x$-component residual stresses

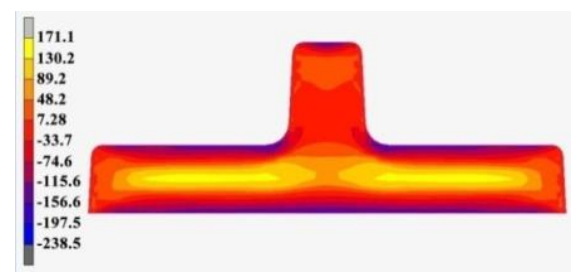

Fig. 7 FEM result of $y$-component residual stresses

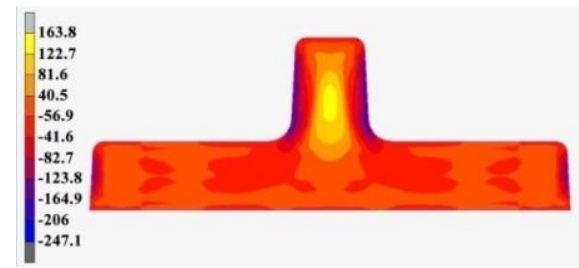

Fig. 8 FEM result of $z$-component residual stresses

Fig. 9 shows the distribution of $x$-component residual stresses on the cutting plane obtained by contour method, which is in good agreement with FEM result shown in Fig. 6 on the whole. Two paths L1 and L2 throughout the entire thickness of the T-section are selected for comparison of residual stresses obtained by different methods, which corresponding to the cross area and the wing plate area respectively as shown in Fig. 9. The results are illustrated in Fig. 10 and Fig. 11.

In Fig. 10, the stresses in path L1 obtained by contour method and FEM are consistent on the whole. In the measurement result, the maximum compressive stress on the surface is about $-200 \mathrm{MPa}$ and the maximum tensile stress in the cross area is up to $210 \mathrm{MPa}$ (about $48 \mathrm{~mm}$ from the bottom of path L1). It is a hidden danger of deformation to the subsequent machining, and should pay special attention.

In Fig. 11, the stresses in path L2 obtained by contour method, layer removal method, and FEM are consistent on the whole. The distribution of residual stresses in the wing plate area is similar to an arc. In the contour method result, the maximum compressive stress on the surface is about $-150 \mathrm{MPa}$, and the maximum tensile stress in the core is about $150 \mathrm{MPa}$.

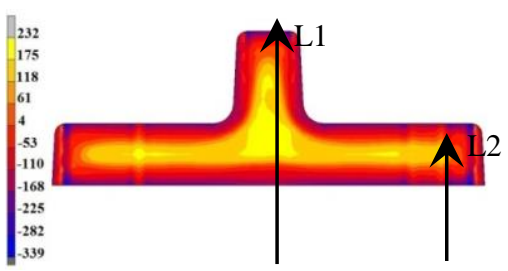

Fig. $9 x$-component residual stresses distribution on the cutting plane measured using contour method

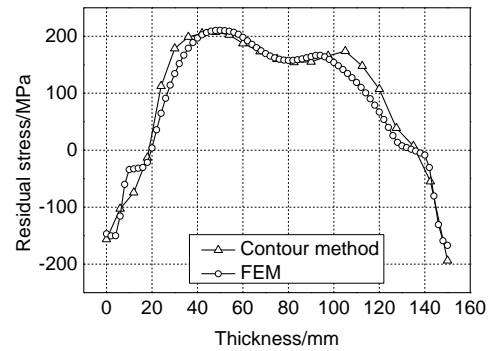

Fig. 10 Distribution of $x$-component stresses along line L1

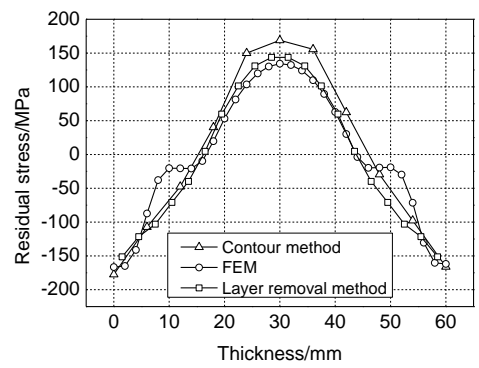

Fig. 11 Distribution of $x$-component stresses along line L2

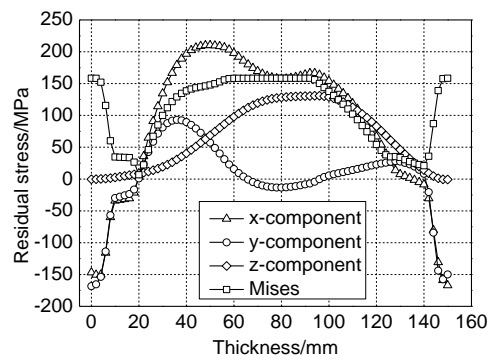

Fig. 12 FEM results of stress distributions along line L1

For further study of the quenching stresses in the forging, FEM result of $x$-, $y$-, $z$-component residual stresses and Mises stresses in path L1 and L2 are shown in Fig. 12 and Fig. 13 respectively. It is evident from Fig. 12 that in the cross-area, $x$ - and $y$-component surface stresses are about $-150 \mathrm{MPa}$, and $z$-component stress is nearly zero. In the core, $x$-component stresses are rather large with a maximum up to $210 \mathrm{MPa}$, while the other two components are much smaller, with a maximum $y$-component stress of about $80 \mathrm{MPa}$ and maximum $z$-component stress of about $110 \mathrm{MPa}$. It is evident from Fig. 13 that in the wing plate area, the distributions of $x$ - and $y$-component stresses are almost the same. The maximum tensile stress in the core is about $150 \mathrm{MPa}$, and the maximum compressive stress on the surface is about $-150 \mathrm{MPa}$, while $z$-component stresses are nearly negligible. 


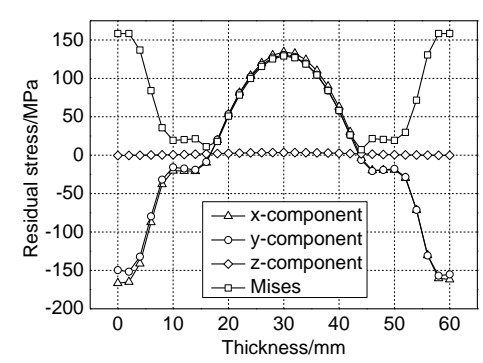

Fig. 13 FEM results of stress distributions along line L2

In Fig. 12 and Fig. 13, the distributions of Mises equivalent stresses in path $\mathrm{L} 1$ and $\mathrm{L} 2$ are similar, stresses at any point of $\mathrm{L} 1$ and $\mathrm{L} 2$ are below the yield strength of $\mathrm{Al}$ 7050 at the end of quenching, which matches the Von Mises yield criterion as Eq. (2), and stresses in the surface layers and core are close to the yield strength. While the distributions of $x$-, $y$ - and $z$-component stresses in path $\mathrm{L} 1$ is quite different from L2. That is mainly because of the difference of heat transfer boundary conditions during the quenching process. In the wing plate the heat transfer is mainly occurs symmetrically on the top and bottom surfaces, resulting symmetrical distribution of $x$-, $y$ - and $z$-component stresses in the thickness direction. While in the cross-area the heat transfer occurs on the top, bottom, left and right surfaces, which lead to a rising of $x$ - and $z$-component stresses and a decline of $y$-component stresses. The results can be verified in Fig. 6-8.

$$
\sigma_{s}=\sqrt{\frac{1}{2}\left[\left(\sigma_{1}-\sigma_{2}\right)^{2}+\left(\sigma_{1}-\sigma_{3}\right)^{2}+\left(\sigma_{2}-\sigma_{3}\right)^{2}\right]},
$$

According to the geometric characteristics of the forging, directions of the three principal stresses can be considered approximately coincident with the $x$-, $y$ - and $z$ - directions. In path $\mathrm{L} 2$, as $\sigma_{1}$ and $\sigma_{2}$ are nearly equal, and $\sigma_{3} \approx 0$, it can be deduced $\sigma_{1} \approx \sigma_{2} \leq \sigma_{\mathrm{s}}=158.4 \mathrm{MPa}$ based on Von Mises criteria as Eq. (2), i.e. absolute values of the three principle stresses will not exceed the yield strength. The same is true for surface stresses in path L1. For inner stresses in path $\mathrm{L} 1$, as $\sigma_{1}$ is larger than $\sigma_{2}$ and $\sigma_{3}$, and $\sigma_{3} \neq 0$, thus $\sigma_{1}$ is rather large.

$x$-component surface stresses on the above analyzed T-section of the forging obtained by contour method, X-ray diffraction and FEM are compared in Fig. 14 and Fig. 15. It is evident from the figures that, the surface stresses of X-ray diffraction result and FEM result are very close, while the contour method result is quite different, and the maximum difference reaches $42 \%$. The difference is mainly due to experimental error. In the contour method experiment, surface profile measurement near the edge of

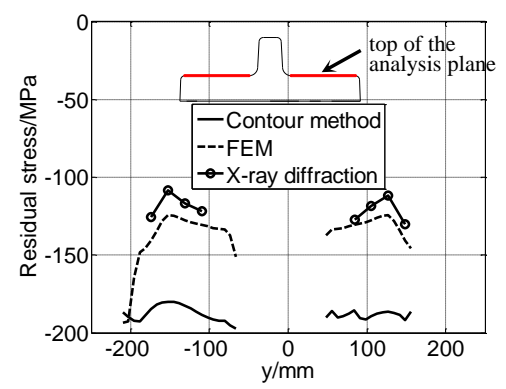

Fig. 14 Stresses at the top of the cutting plane

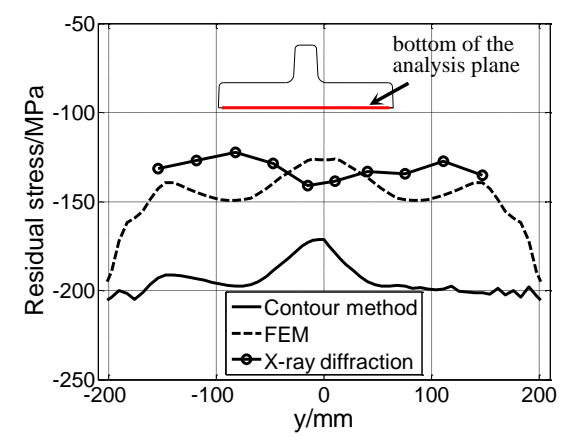

Fig. 15 Stresses at the bottom of the cutting plane

the T-shaped cutting surface is difficult, thus, interpolation is needed to correct the contour datum corresponding to the cutting surface edge, which will inevitably introduce error. Thus, X-ray diffraction measurement of surface stresses should be taken into consideration to fully understand the distribution of quenching stresses of the T-section 7050 aluminum alloy forging.

\section{Conclusions}

1. Quenching residual stresses in the T-section 7050 aluminum alloy forging presents a layering distribution, with compressive stresses on surface and tensile stresses in the core, and the layers are approximately parallel to the surface. The maximum tensile stress normal to the Tsection in the core is up to $210 \mathrm{MPa}$, which is a hidden trouble of machining deformation.

2. The results of internal residual stresses of experiment and FEM are in good agreement on the whole. In the cross-area of the forging, surface stresses of $x$ - and $y$-component are about $-150 \mathrm{MPa}$ and $z$-component is nearly zero, and in the core, the maximum stresses of $x-, y$ - and $z$-component are respectively $210 \mathrm{MPa}, 80 \mathrm{MPa}$ and $110 \mathrm{MPa}$. In the wing plate area, $x$ - and $y$-component stresses are almost the same, with maximum tensile stresses of about $150 \mathrm{MPa}$ in the core and maximum compressive stresses of about $150 \mathrm{MPa}$ on the surface, and nearly negligible $z$-component stresses. Affected by the measurement principle and experiment errors, surface stresses obtained by contour method and layer removal method are larger than FEM and X-ray diffraction, and should be corrected by $\mathrm{X}$-ray diffraction.

3 . The combination of contour method, layer removal method, X-ray diffraction and FEM was successfully applied to obtain the residual stresses distributions in complicated component as T-section 7050 aluminum alloy forging. It is evident that the combination method is a reliable technique to provide an accurate description of the quenching residual stresses distribution in the forging.

\section{Acknowledgments}

This study is supported by the National Natural Science Foundation of China (No.: 51405520, 51327902), the National Basic Research Program of China (No.: 2012CB619505), and the International S \& T Cooperation Program of China (No.: 2014DFA51250).

\section{References}

1. Prime, M.B.; Hill, M.R. 2002. Residual stress, stress relief, and inhomogeneity in aluminum plate, Scripta 
Materialia 46: 77-82. http://dx.doi.org/10.1016/S1359-6462(01)01201-5.

2. Zhang, X.M.; Deng, Y.L.; Zhang, Y. 2015. Development of high strentgh aluminum alloys and processing techniques for the materials, Acta Metallurgica Sinica 51(3): 257-271. http://dx.doi.org/10.11900/0412.1961.2014.00406.

3. Koc, M.; Culp, J.; Altan, T. 2006. Prediction of residual stresses in quenched aluminum blocks and their reduction through cold working processes, Journal of Materials Processing Technology 174: 342-354. http://dx.doi.org/10.1016/j.jmatprotec.2006.02.007.

4. Prime, M.B.; Newborn, M.A.; Balog, J.A. 2003. Quenching and cold-work residual stresses in aluminum hand forgings: contour method measurement and FEM prediction, Materials Science Forum 426-432: 435-440. http://dx.doi.org/10.4028/www.scientific.net/MSF.426432.435 .

5. Withers, P.J.; Turski, M.; Edwards, L.; Bouchard, P.J.; BUTTLE, D.J. 2008. Recent advances in residual stress measurement, International Journal of Pressure Vessels and Piping 85: 118-127. http://dx.doi.org/10.1016/j.ijpvp.2007.10.007.

6. Xu, W.F.; Liu, J.H.; Zhu, H.Q. 2011. Analysis of residual stresses in thick aluminum friction stir welded butt joints, Materials and Design 32(4): 2000-2005. http://dx.doi.org/10.1016/j.matdes.2010.11.062.

7. Hatamleha, O.; Dewald, A. 2009. An investigation of the peening effects on the residual stresses in friction stir welded 2195 and 7075 aluminum alloy joints, Journal of Materials Processing Technology 209(10): 4822-4829. http://dx.doi.org/10.1016/j.jmatprotec.2008.12.010.

8. Deplus, K.; Simar, A.; Haver, W.V.; Meester, B.D. 2011. Residual stresses in aluminium alloy friction stir welds, The International Journal of Advanced Manufacturing Technology 56(5): 493-504. http://dx.doi.org/10.1007/s00170-011-3210-0.

9. Greving, D.J.; Rybickl, E.F.; Shadley, J.R. 1994. Through-Thickness Residual Stress Evaluations for Several Industrial Thermal Spray Coatings Using a Modified Layer-Removal Method, Journal of Thermal Spray Technology 3(4): 379-388. http://dx.doi.org/10.1007/BF02658983.

10. Prime, M.B.; Gnäupel-herold, T.; Baumann, J.A.; Lederich, R.J.; Bowden, D.M.; Sebring, R.J. 2006. Residual stress measurements in a thick, dissimilar aluminum alloy friction stir weld, Acta Materialia 54: 4013-4021. http://dx.doi.org/10.1016/j.actamat.2006.04.034.

11. Zhang, Y.; Ganguly, S.; Edwards, L.; Fitzpatrick, M.E. 2004. Cross-sectional mapping of residual stresses in a VPPA weld using the contour method, Acta Materialia 52: 5225-5232. http://dx.doi.org/10.1016/j.actamat.2004.07.045.

12. Yu, K.Q.; Yang, Y.F.; Chen, B.; Zheng, X.W. 2014. Research on measuring residual stresses in aluminium stretch-bending workpiece by using contour method, Aviation Precision Manufacturing Technology 50(5): 29-32. http://dx.doi.org/1003-5451(2014)05-0029-04.

13. Zhang, Z.; Li, L.; Yang, Y.F.; Ma, L.D.; Ma, Y.L. 2014. Residual stress measurement in die forging of 7050-T74 aluminum alloy using contour method, The Chinese Journal of Nonferrous Metals 24(12): 3002-
3008 .

http://dx.doi.org/1004-0609(2014)12-3002-07.

14. Prime, M.B. 2001. Cross-sectional mapping of residual stresses by measuring the surface contour after a cut, Journal of Engineering Materials and Technology 123(2): 162-168.

http://dx.doi.org/ 10.1115/1.1345526.

15. Withers, P.J. 2007. Mapping residual and internal stress in materials by neutron diffraction, Comptes Rendus Physique 8: 806-820. http://dx.doi.org/10.1016/j.crhy.2007.09.015.

16. Santisteban, J.R.; Daymond, M.R.; James, J.A.; Edwards, L. 2006. ENGIN-X: a third-generation neutron strain scanner, Journal of Applied Crystallography 39: $812-825$. http://dx.doi.org/10.1107/S0021889806042245.

17. Wang, Z.T.; Tian, R.Z. 2005. Handbook of aluminum alloys and their processing, Central South University Press, Changsha.

18. Pagliaro, P.; Prime, M.B.; Robinson, J.S.; Clausen, B.; Swenson, H.; Steinzig, M.; Zuccarello, B. 2010. Measuring Inaccessible Residual Stresses Using Multiple Methods and Superposition, Proceedings of the Society for Experimental Mechanics, Inc. 51(7): 11231134.

http://dx.doi.org/10.1007/s11340-010-9424-5.

Gong Hai, Wu Yunxin, Zhang Tao, Liu Yaoqiong,

Li Chen, Ji Hao, Yi Shouhua, Cao Minghui, Xiao Feng

\section{QUENCHING RESIDUAL STRESSES IN T-SECTION 7050 ALUMINUM ALLOY FORGING}

S u m m a r y

Distribution of quenching residual stresses in $\mathrm{T}$ section 7050 aluminum alloy forging was obtained using a combination method of finite element method (FEM), contour method, layer removal method and X-ray diffraction. The results show that, experimental results and FEM result of internal residual stresses are in good agreement. While surface stresses obtained by layer removal method and contour method are different with X-ray diffraction and FEM, thus X-ray diffraction of surface stresses should be taken into consideration to fully understand the distribution of quenching stresses in the T-section 7050 aluminum alloy forging. Moreover, surface residual stresses are compressive of about $-150 \mathrm{MPa}$, while residual stresses in the core are tensile with a maximum up to $210 \mathrm{MPa}$, which is very harmful for the subsequent machining.

Keywords: aluminum alloy, residual stress, finite element method, X-ray diffraction, contour method, layer removal method.

Received February 25, 2016 Accepted June 08, 2017 